\title{
Diode Laser Excited Optogalvanic Spectroscopy of Glow Discharges
}

\author{
C. M. Barshick, R. W. Shaw, A. Post-Zwicker, \\ J. P. Young, and J. M. Ramsey
}

Chemical \& Analytical Sciences Division, Oak Ridge National Laboratory, P.O. Box 2008, Oak Ridge, TN 37831-6142

\begin{abstract}
The development of diode-laser-excited isotopically-selective optogalvanic spectroscopy (OGS) of uranium metal, oxide and fluoride in a glow discharge (GD) is presented. The technique is useful for determining isotopic ratios of $235 \mathrm{U} /(235 \mathrm{U}+238 \mathrm{U})$ in the above samples. The precision and accuracy of this determination is evaluated, and a study of experimental parameters pertaining to optimization of the measurement is discussed. Application of the GD-OGS to other f-transition elements is also described.
\end{abstract}

\section{INTRODUCTION}

The application of diode lasers to isotopically-selective atomic spectroscopy has been of interest to us for several years. Previously we carried out isotopicallyselective resonance ionization mass spectrometry of lanthanum using diode lasers in the first step of a multistep of the resonant excitation.(1) At the last RIS meeting, our initial studies of the use of diode laser excitation for isotopically-selective optogalvanic spectroscopy (OGS) of uranium in a glow discharge (GD)(2) was presented. The study of uranium GD-OGS continues to be a main area of investigation. The technique of using diode lasers for GD-OGS studies has applications to other elements and for other purposes besides analytical determinations. Our work in these areas, particularly with lanthanides and uranium is the subject of this report.

\section{EXPERIMENTAL}

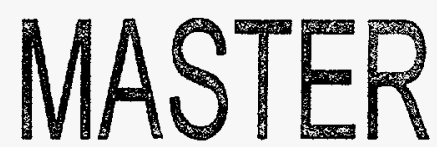

The details of the experimental set-up for these studies have been described elsewhere $(2,3,4)$ but are summarized here. A demountable GD cell containing a seethrough cathode was used. The cathode was a metal or composite hollow cylinder approximately $5 \mathrm{~mm}$ O.D., $2.4 \mathrm{~mm}$ I.D., and $2.5 \mathrm{~mm}$ in length. The composite cathodes were pressed from a 50-50 weight \% mixture of a sample power and a metal powder (Ag or a mixture of Ag-Ta). The cell body served as the counter electrode of the discharge. The OGS signal was generated by excitation with either an argon-ion laser-pumped titanium:sapphire (Ti:S) ring laser or with semiconductor diode lasers. The power of these lasers was controlled in the range of 30 to several hundred $\mathrm{mW}$. The laser radiation was chopped at $1000 \mathrm{~Hz}$ and directed as a focused beam ( $50 \mu$ dia.) through the cathode. For OGS measurement, the ac component of the cathode voltage is observed on an oscilloscope and a lock-

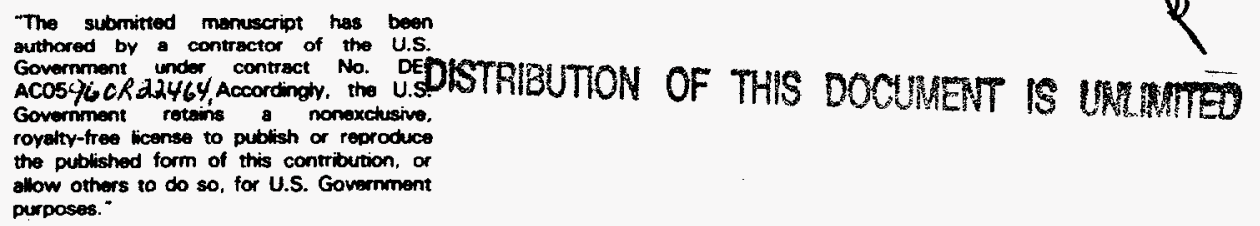




\section{DISCLAIMER}

Portions of this document may be illegible in electronic image products. Images are produced from the best available original document. 


\section{DISCLAIMER}

This report was prepared as an account of work sponsored by an agency of the United States Government. Neither the United States Government nor any agency thereof, nor any of their employees, makes any warranty, express or implied, or assumes any legal liability or responsibility for the accuracy, completeness, or usefulness of any information, apparatus, product, or process disclosed, or represents that its use would not infringe privately owned rights. Reference herein to any specific commercial product, process, or service by trade name, trademark, manufacturer, or otherwise does not necessarily constitute or imply its endorsement, recommendation, or favoring by the United States Government or any agency thereof. The views and opinions of authors expressed herein do not necessarily state or reflect those of the United States Government or any agency thereof. 
in amplifier. The output of the lock-in was digitized by the Ti:S control computer or a separate computer in the case of the diode lasers.

\section{RESULTS AND DISCUSSION}

Previously we reported the observation of GD-OGS signals for uranium or its oxide at wavelengths of 778.9 and $776.19 \mathrm{~nm}$. $(2,3)$ We have now carried out precision and accuracy studies for the measurement of $235 \mathrm{U} /(235 \mathrm{U}+238 \mathrm{U})$ isotope ratios in depleted and enriched uranium, uranium oxide, and uranium fluoride with diode laser excitation. An example of these results, at a wavelength of $776.19 \mathrm{~nm}$, is shown in the calibration curve given in Figure 1. As can be seen the data shows a good linear fit ( $R$ value of 0.99977 for a slope of 1.019 ) from depleted to $20 \%$ enriched (in $235 \mathrm{U}$ ) uranium oxide. The precision for the lower ratios is poorer than for the enriched sample. This is to be expected since the OGS signal of $235 \mathrm{U}$ is proportional to its concentration. In this and other of our GD-OGS studies of uranium, it is notable that uranium oxide, fluoride or metal can be analyzed equally well. Run-to-run, day-to-day, and sample-to-sample precision was evaluated using a $30 \mathrm{~mW}$ diode laser at $776.14 \mathrm{~nm}$; the beam was focused to give $400 \mathrm{~W} / \mathrm{cm}^{2}$ in the cathode.(4) The sample was a NIST-200 uranium oxide, $20 \%$ 235U. Run-to-run relative standard deviation (RSD) of the $235 \mathrm{U} /(235 \mathrm{U}+238 \mathrm{U})$ ratio at $1 \sigma$ ranged from $\pm 1.9 \%$ to $5.5 \%$ over 5 consecutive days. These data yielded a mean precision of $\pm 2.6 \%$ RSD. Sample-to-sample precision, based on a number of analyses of three different sample cathodes was $\pm 3.5 \%$ RSD. Determination of uranium isotope ratios using GD-OGS are therefore adequate for screening measurements. The sample is also available for a more precise isotopic ratio determination if that becomes necessary.

Although it is apparent from Figure 1 that a reasonable estimation of low $235 \mathrm{U} /(235 \mathrm{U}+238 \mathrm{U})$ isotope ratios can be made using this technique, it would be advantageous to improve the precision. The precision is ultimately based on the signal-to-noise ratio, and one way to improve this aspect would be to increase the signal. We therefore investigated several diode-laser assessable OGS transitions looking for an enhanced OGS signal; a reasonable isotope shift (I.S.) was also required. A promising uranium transition at $831.84 \mathrm{~nm}$ was found. An OGS spectrum, average of 5 scans, for depleted uranium metal powder is shown in Figure 2. The I.S. for the two isotopes is $10.1 \mathrm{GHz}$, compared with $-12.6 \mathrm{GHz}$ for $776.19 \mathrm{~nm}$; tunable diode lasers in this wavelength region can readily be obtained with a power of $150 \mathrm{~mW}$. Evaluation of the measurement precision has been carried out with depleted uranium oxide at $831.84 \mathrm{~nm}$; the laser power was 84 $\mathrm{mW}$. The measured $235 \mathrm{U} /(235 \mathrm{U}+238 \mathrm{U})$ ratio was found to be 0.0026 ; the thermal ionization mass analysis value was 0.0027 . Run-to-run reproducibility of the

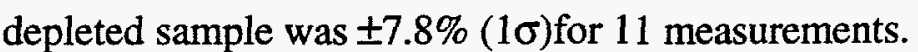

A prototype, transportable instrument which should lead to a field determination of uranium isotope ratios using GD-OGS has been designed and fabricated. The instrument makes use of capillary tubing and a mechanical vacuum pump to control the pressure and flow rate of argon gas in the GD cell. A commercial diode laser or external cavity diode laser unit provides the optical excitation. The signal is processed by a lock-in amplifier, and the wavelength of the output is monitored by a commercial uranium hollow cathode lamp. The entire analytical operation is controlled by a notebook computer that calibrates wavelength, provides a sweep current to the diode laser for wavelength scanning, collects and assesses the data, and determines the reliability of the measurement. 
The prototype is currently being evaluated for application to uranium and other $\mathrm{f}$ transition elements.

There appears to be an art connected with generating useful glow discharge for OGS studies. Besides the obvious parameters of pressure, flow rate, and voltage, there are other parameters such as cathode composition, GD cell geometry, ubiquitous presence or generation of $\mathrm{H}_{2} \mathrm{O}$, etc., that influence the quality of the discharge and therefore the intensity of the OGS signal. We have studied some of these effects. They have been reported in detail(5) and are summarized here. Although metal samples generally make a satisfactory discharge, salts (insulators) require the addition of an electrical conductor to maintain a useful discharge. We originally made our uranium oxide cathodes by pressing a 50-50 weight \% mixture of oxide and silver metal powder into a pellet. The silver serves two purposes. Being very malleable, it helps make a stable pellet, and it makes the cathode electrically conductive. An ideal metal additive to a uranium oxide sample should also exhibit a strong bond with atomic oxygen and have a high sputtering rate in the discharge. We examined the influence of $\mathrm{Ag}$, $\mathrm{Ti}$, and $\mathrm{Ta}$ metal, and mixtures thereof on the intensity of the OGS signal of uranium in an oxide sample; the $831.84 \mathrm{~nm}$ transition was used. We found that a 50-50 weight \% Ag-Ta mixture was suitable for our purpose as it provides a compromise of sputter rate and stability of the metal-oxygen bond to compete with the stability of the U-O bond.

Many of our laboratory studies of the uranium GD-OGS technique have used a liquid nitrogen cooled coil placed in the vicinity of the cathode to improve the uranium OGS signal. The cooled coil effectively removes condensed vapors from the region of the cathode. It will not be convenient to have liquid nitrogen cooling in a fieldable apparatus, so an evaluation of a non-evaporatable $\mathrm{Zr} / \mathrm{V} / \mathrm{Fe}$ alloy getter (Model ST172/NP/HITS-L/7.5-7/150C, SAES Getters, Colorado Springs, CO) was carried out. Relative $U$ signal improvements for uranium oxide as a function of various parameters are given in Table 1, the cathode in this study contained a mixture of oxide and $\mathrm{Ag}$.

TABLE 1. Enhancement of 238U OGS Signal at $831.84 \mathrm{~nm}$ as a Function of GD Operating Condition.

\begin{tabular}{|c|c|c|c|}
\hline Condition & $\begin{array}{l}\text { Time from } \\
\text { Start, min. }\end{array}$ & $\begin{array}{c}\text { Relative OGS } \\
\text { Signal }\end{array}$ & $\begin{array}{l}\text { Discharge } \\
\text { Current, mA }\end{array}$ \\
\hline Initial discharge & $(0)$ & $(1.00)$ & 13.76 \\
\hline One hour later & 60 & 3.2 & 14.83 \\
\hline $\mathrm{Zr} / \mathrm{V} / \mathrm{Fe}$ alloy getter & 15 & 6.2 & 14.79 \\
\hline Liquid-nitrogen cooling & 15 & 16.6 & 14.65 \\
\hline
\end{tabular}

Although the signal is strongest with liquid-nitrogen cooling, it is improved significantly with the getter that will be incorporated in the fieldable instrument. We have also carried out other time-related studies with a cathode that contained uranium oxide with the 50-50 weight \% Ta and Ag which demonstrate that after discharge initiation, the uranium OGS signal reaches maximum intensity in about 30 minutes with the $\mathrm{Zr} / \mathrm{V} / \mathrm{Fe}$ getter compared to one hour without the getter.

The technique of GD-OGS should be applicable to most elements or compounds provided that a laser excitation source is available. We have generally limited our studies to OGS atomic transitions that could be excited by diode lasers. We have further limited our studies to the lanthanides and uranium. Again, with any of the f-transition elements, a number of transitions accessible to diode lasers 
should be available. We have carried out some survey GD-OGS studies of Ce, Dy, and $\mathrm{Gd}$. We are planning a study with $\mathrm{Ce}$ that can give information pertaining to GD characteristics. In preliminary studies we have observed several accessible OGS transitions for Ce; they are given in Table 2.

\section{TABLE 2. Observed GD-OGS Transitions of Cerium}

$\begin{array}{ccc}\text { Wavelength } & \text { Spectrum } & \text { Transition, cm-1 } \\ 7913.52 & & \\ 7927.72 & \text { I } & 6663-19296 \\ 8025.56 & \text { I } & 4455-17066 \\ 8220.70 & \text { II } & 0-12457 \\ 8224.29 & \text { I } & 3210-15371 \\ 8254.89 & \text { II } & 3704-15859 \\ & \text { I } & 0-12114\end{array}$

There is a ground state (g.s.) transition for both $\mathrm{Ce} I$ and $\mathrm{Ce} I I$ which we will utilize to provide information on the relative population density of these two oxidation states. Although the idea for this study came from our diode laser work, we plan to excite them with the $\mathrm{Ti}: \mathrm{S}$ laser to minimize experimental variables, such as laser power. There have been previous studies directed to characterizing hollow cathode discharges.(6) They were generally directed to profiling free atom density in the volume element for an active discharge; this was done by atomic absorption or emission. The ion population was measured, in general, by GDMS. In the Ce example given above, we plan to study directly and by the same technique, GDOGS, the ratio of atom to ion population as a function of discharge conditions. From this type of information it should be possible to provide experimental conditions that favor ion or atom population in order to meet experimental desires, e.g., mass spectrometry or OGS. Another advantage of this approach is that it samples only the g.s. population of both species.

\section{ACKNOWLEDGEMENTS}

Research sponsored by U.S. Department of Energy, Office of Research and Development. Oak Ridge National Laboratory is managed by Lockheed Martin Energy Research Corporation for the U.S. Department of Energy under contract DE-AC05-960R22464.

\section{REFERENCES}

1. Shaw, R. W.; Young, J. P.; Smith, D. H.; Bonanno, A. S.; and Dale, J. M.; Phys. Rev. A, 41, 2566 (1990).

2. Young, J. P.; Barshick, C. M.; Shaw, R. W.; and Ramsey, J. M.; Amer. Inst. of Physics Conf. Proceedings 329 (Reson. Ioniz. Spectrosc. 1994), H.-J. Kluge, J. E. Parks, K. Wendt, eds., p. 111.

3. Barshick, C. M.; Shaw, R. W.; Young, J. P.; and Ramsey, J. M.; Anal. Chem., 66, 4154 (1994).

4. Barshick, C. M.; Shaw, R. W.; Young, J. P.; and Ramsey, J. M.; ibid. 67, 3814 (1995).

5. Shaw, R. W.; Barshick, C. M.; Jennings, L. W.; Young, J. P.; and Ramsey, J. M.; Rapid Comm. in Mass Spectrometry, Vol. 10, 316 (1996). 